\title{
Utilization of Granite Powder as a Filler for Polybutylene Terepthalate Toughened Epoxy Resin
}

\author{
H. V. Ramakrishna and S. K Rai* \\ Department of Polymer Science, Sir M.V.P.G Center, University of Mysore \\ Tubinakere Industrial area, Mandya, Karnataka, INDIA 571402 \\ *Correspondence Author's Email: Sheshappa_rai@rediffmail.com
}

\begin{abstract}
:
Granite powder filled epoxy and polybutylene terephthalate (PBT) toughened epoxy composites were prepared. The variation of the mechanical properties such as tensile, flexural, compressive strengths and impact with filler content was evaluated. The effect of the silane coupling agent on the properties of these composites and the chemical resistance and water absorption of these composites was studied. The composites with 50\% granite powder showed better properties.
\end{abstract}

Keywords: Granite powder, PBT, toughening, tensile, flexural, compression, Impact, chemical resistance, composites

\section{INTRODUCTION}

Epoxy is widely used as a matrix material for making many composites. However, it is brittle in nature and has poor resistance to crack propagation [1]. Many investigators have used various toughening agents with epoxy, such as liquid amine terminated [2], carboxyl terminated [3] and hydroxyl terminated [4] copolymers of butadiene and acryloitrile. Recently many investigators are using thermoplastics as toughening agents for epoxy. Among them, polybutylene terephthalate (PBT) is found to be effective due to its phase transformation toughening mechanism [5].

In order to reduce the cost of the composites, cheaper, naturally occurring fillers such as $\mathrm{CaCO}_{3}$, silica, talc, clay [6], flyash [7], cellulose based fillers [8], and kaolin $[9,10]$ have been widely used. Utilizing locally available resources is a cost effective source of filler material. For example, granite powder is generated in large quantities during the sizing of granite slabs. The authors used this waste granite powder generated by the local industries as filler in epoxy and PBT toughened epoxy. The authors determined the mechanical properties of these composites and studied their variation with filler content. The authors also studied the chemical resistance and water absorption of these composites to assess their performance. 


\section{EXPERIMENTAL}

\section{Materials}

In the present work, a commercially available epoxy resin DGEBA procured from M/s Vantico Ltd. Bombay was used as the polymer matrix. Triethylene tetramine was used as the hardener. The coupling agent triethoxy methyl silane, for modifying the granite powder, was procured from E Merck. Commercially available PBT was obtained from local suppliers. Granite powder was collected from local granite industries. The particle size of the granite powder ranged from 1 to 100 micrometers and the chemical composition is given in Table 1 .

\section{Preparation of the Composites}

The granite powder was washed thoroughly with water then dried in an oven at $120{ }^{\circ} \mathrm{C}$ for $2 \mathrm{~h}$ to remove any moisture before using it as filler for epoxy resin. A $1 \%$ solution of the silane coupling agent in acetone was used with $100 \mathrm{gm}$ of filler. The granite powder was mixed with the coupling agent solution for 30 minutes to ensure uniform distribution of the coupling agent. The treated granite powder was then dried at $60{ }^{\circ} \mathrm{C}$ in an oven for about $1 \mathrm{~h}$ to allow complete evaporation of the acetone. The density of the granite powder was found to be 2.19 as determined by ASTM standard.

For blending of PBT and epoxies, the PBT pellets were dissolved in dichloromethane and the solution was poured to the beaker containing epoxy resin. The amount of PBT in epoxy resin was varied from 1 to $4 \%$ by weight. Above this content, the epoxy resin became highly viscous. The resin to hardener ratio was maintained at 100:10 parts by weight as suggested by the manufacturer. The dichloromethane was evaporated by heating resin mixture at $80^{\circ} \mathrm{C}$. After complete evaporation of the dichloromethane, the mixture of PBT and epoxy resin was stirred at $150{ }^{\circ} \mathrm{C}$ continuously for $1 \mathrm{~h}$ and then cooled to room temperature. Before curing, the mixtures were degassed and poured into moulds. The epoxy and hardener system was cured at room temperature for $24 \mathrm{~h}$ and then post cured at 100 ${ }^{\circ} \mathrm{C}$ for $2 \mathrm{~h}$ to ensure complete curing.

\section{Testing of Composites}

Laminates of the composites under study were made by room temperature curing for 24 hours in a 260x130x3 mm Teflon mould. The laminates were cut to the required specimen size as per the ASTM standards for mechanical testing. All the samples were post cured at $100{ }^{\circ} \mathrm{C}$ in an oven for $2 \mathrm{~h}$ to ensure complete curing before subjecting them to mechanical testing. The specimens were also made in the presence of the coupling agent. 
The tensile, compressive and flexural modulus and strength were determined using a Lloyd's LR $100 \mathrm{KN}$ type universal testing machine. The impact tests of the un-notched specimens were carried out using an Izod impact tester. For each test, ten specimens of each type were used and the average value is reported.

The chemical resistance of the blend matrix and the composites was studied as per ASTM D 543 method. For this purpose, two strong acids (conc. $\mathrm{HCl}$ and conc. $\mathrm{HNO}_{3}$ ), lactic acid, and glacial acetic acid; aqueous solutions of $40 \% \mathrm{NaOH}$, and $20 \%$ of $\mathrm{Na}_{2} \mathrm{CO}_{3}$; and three organic solvents (benzene, carbon tetrachloride, and toluene) were selected. The pre-weighed samples were dipped in chemicals for $24 \mathrm{~h}$, removed, washed thoroughly with distilled water and dried immediately by pressing them on both sides by filter paper. The final weight of the samples and percentage weight loss/gain was determined. The chemical test was repeated for ten samples in each case and the average value was reported.

For the water absorption test, rectangular specimens with dimensions of $25.4 \mathrm{~mm} \times 76.2 \mathrm{~mm}$ were cut from the laminates. Three replicate specimens were tested and the results are presented as average. The samples were dried in an oven at $50{ }^{\circ} \mathrm{C}$ for $24 \mathrm{~h}$, cooled in a decicator and immediately weighed to the nearest $0.001 \mathrm{gm}$. In order to measure the water absorption of the composites, all samples were immersed in water for about $24 \mathrm{~h}$ at room temperature as described in ASTM D 570 - 99 (ASTM 1999) procedure. Excess water on the surface of the samples was removed before weighing. The percentage increase in weight during immersion was calculated to the nearest $0.01 \%$ as follows.

Wet Wt. - Reconditioned Wt.

Increase in weight $\%=\longrightarrow \quad$ X 100

Reconditioned Wt.

\section{RESULTS AND DISCUSSION}

In order to optimize the content of PBT in toughening the epoxy, blends with different percentages of PBT were prepared and their mechanical properties determined. These values are presented in Table 2. From this data it is evident that the tensile, flexural, compressive and impact strength are maximum when the PBT content is $2 \%$ in the blend. At $2 \%$ PBT content, the increment in tensile, flexural, compressive and impact strength over the pure epoxy matrix are found to be $51.7 \%, 17.5 \%, 53.7 \%$ and $33.3 \%$ respectively. When the PBT content was increased above $2 \%$, the mechanical parameters decreased. This behavior may be due to the fact that as the fraction of PBT in epoxy increases, the dispersing phase of PBT in the epoxy rich matrix increases, which hinders the cross linking of 
epoxy with amine hardener thereby decreasing the total strength of the system. Thus 2\% PBT is found to be optimum for effective toughening of epoxy.

The variation of tensile strength, modulus and \% elongation at break of the composites with untreated and coupling agent treated granite in epoxy and with coupling agent treated granite powder in 2\% PBT toughened epoxy is shown in Figs. 1-3 respectively. From these figures, it is evident that in all these cases, the tensile properties are found to increase with filler content up to $50 \%$ and decreased beyond this content. The increase in the tensile properties with filler content (up to $50 \%$ ) may be due to the restriction of the mobility and deformability of the matrix with the introduction of mechanical restraint, and the filler particle size. Most investigators have enumerated that particle size is inversely related to reinforcing character and that an increase in surface area (as a consequence of reduced particle size) increases the composite mechanical properties [11,12]. Simultaneously, the higher stiffness of granite powder as compared to the epoxy matrix in which the filler is dispersed may also contribute to the above enhancement. The decrease in the tensile properties beyond $50 \%$ filler content may be due to the non-wetting of the filler particles with the matrix and the non-uniform distribution of filler particles in the cured matrix. Further, it is observed that the coupling agent on the filler and PBT in the matrix improved the tensile strength and modulus. Besides, from Fig.3, it is found that the \% elongation at break decreased with filler content. This is understandable as the filler is stiffer than the matrix.

The variation of flexural strength, flexural modulus, compressive strength, and compressive modulus for the composites under study with filler content are presented in Figs 4, 5, 6, and 7 respectively. From these figures it is evident that the flexural and compressive properties are higher when coupling agent and PBT were used in the composites. The coupling agent is expected to improve the stress transfer between the matrix and the filler by the formation of a stronger filler/matrix interface. A similar observation was made by Wong et.al [13] in the case of flyash/polypropylene composites. The trend of the variation of flexural and compressive properties with filler is similar to that of the variation of tensile properties. Further, the enhanced compressive strength properties of the composites over that of the matrix may be due to the stiff nature of the filler. In addition, the presence of PBT and platelet shape of granite powder might have also contributed to such an increase [6]. It was assumed that the space between the granite powder particles was filled with the blend matrix, thus minimizing the presence of voids and bubbles and leading consequently to an increase in both strength and modulus.

Incorporation of a rigid filler may enhance or deteriorate the impact properties of composites $[14,15]$. Impact strength is an indication of tolerability for a sudden impact. When a composite is subjected to an impact, rapid crack 
propagation is initiated through the material. When such crack propagation encounters a filler particle in the filled composite, the filler can absorb the energy and stop the crack propagation if the filler-matrix interaction is strong. On the other hand, if the interfacial adhesion is poor, the filler particle cannot resist crack propagation as effectively as the polymer alone and consequently a catastrophic crack propagates, lowering the impact strength of the composite as loading increases. In the filled composites, as the filler loading increases the tendency for agglomeration also increases. As filler agglomeration increases, interfacial adhesion becomes weaker leading to weaker interfacial regions. These agglomerates act as stress concentration points or crack initiation sites. Therefore reduction in impact strength with increasing filler content is expected.

The variation of the impact strength of the untreated and coupling agent treated granite in epoxy and the coupling agent treated granite in $2 \%$ PBT toughened epoxy is shown in Fig. 8. Here also it is observed that the impact strength is higher when the filler was treated with the coupling agent and the matrix was toughened with PBT. It is also observed that in all cases the impact strength increased up to 50\% filler loading and decreased with further increment in the filler content. This is due to the fact that the $50 \%$ filler content is the maximum filler content and, as said earlier, for further increments the impact strength decreased. The increased impact strength in the case of 2\% PBT toughened epoxy treated granite powder composite is due to increased toughness from introducing PBT into the epoxy matrix, thereby reducing the brittleness of the epoxy resin. The increase in toughness of PBT toughened epoxy seems to arise from a combination of processes that include primary crack bridging, crack bifurcation, crack path alteration, formation of steps and welts and secondary crack bridging. Other factors include ductile fracture of the dispersed PBT particles in epoxy rich matrix and phase transformation mechanisms [16]. According to Griffth's theory, a large aggregate is a weak point, which lowers the stress required for the composite to fracture. As Nakagawa and Sano [17] have shown, the presence of fine particles dispersed with in the matrix make plastic deformation easier. So, during the fracture of a composite in which the mineral filler is fine and well dispersed, i.e., in which the material is more homogeneous, the stress will have to be bigger to start a micro crack on a particle and impact energy will largely be absorbed by plastic deformation. Hence, good filler dispersion resulting from the coupling agent treatment leads to better impact strength of the composites. This observation clearly suggests that 2\% PBT toughened epoxy treated granite powder composites have better toughness characteristics over untreated and coupling agent treated granite powder/epoxy composites.

The percent weight gain $(+)$ or weight loss (-) data for untreated and coupling agent treated granite powder/epoxy composites immersed in various 
chemical are presented in Table 3. These values for coupling agent treated granite powder/PBT toughened epoxy composites are presented in Table 4. From Table 3, it is clearly evident that weight gain is observed in both the untreated and coupling agent treated granite powder composites. In the case of coupling agent treated granite powder composites, less weight gain is observed when compared to untreated granite powder composites. These results indicate that the addition of the coupling agent is bringing the components closer; as a result, close packing is ensured in the composites. Generally, close packing enhances the chemical resistance of the materials. From Table 4, it is evident that when epoxy was toughened with $2 \%$ PBT weight gain is observed when composites were immersed in acetic acid, hydrochloric acid, nitric acid and lactic acid whereas weight loss was observed when composites were immersed in solvents and alkalis. This weight loss may be due to the slight removal of PBT, which is slightly soluble in organic solvents. The weight gain is understandable as cross-linked systems form threedimensional networks that are chemically more stable.

Water absorption behavior of polymer-filler composites in a particular environment is determined by factors such as processing techniques, matrix and filler characteristics, polymer: filler ratio, and duration of immersion in water. The variation of water absorption by untreated and coupling agent treated granite powder/epoxy and coupling agent treated granite powder/PBT toughened epoxy is presented in Fig. 9. From the figure, it is evident that the water absorption is lower when epoxy was toughened with PBT. Further, the presence of the coupling agent also decreased water absorption. The lower water absorption results indicate that the added coupling agent is bringing the components closer. As a result, close packing of filler and matrix is ensured and the presence of the thermoplastic PBT results in lower water absorption of these composites.

\section{CONCLUSSION}

Toughening epoxy resin with $2 \mathrm{wt} \%$ PBT enhanced tensile, flexural, compression and impact properties. The enhancement was prominent in strength of all the composites, which showed improved matrix filler adhesion by the coupling agent. The mechanical properties of the composites under study were maximized at $50 \%$ granite powder filler content. The composites prepared had good chemical resistance and lower water absorption.

\section{REFERENCES}

1. H.Lee and K. Neville, Hand book of Epoxy resins, Newyork; McGrawHill, 1967

2. G.Levita, A.Marchelli and Bertha E, Polymer, 26 (1985) 1110

3. S.C.Kunz, J.A.Sayre and R.A. Assink, (1982), Polymer, 23 (1982) 1897 
4. S.J.Sankaran, J. Appl.Polym.Sci., 39 (1090) 1635

5. Sangcheol Kim, Won Ho Jo, J. Mater.Sci, 34 (1999) 161

6. H.S.Katz and J.V. Milewski, Hand Book of Fillers and Reinforcements for Plastics, Vannostrand Reinhold, 1978

7. M.Sarojadevi,V.Murugesan,K.Rengaraj,PAnand,Appl.Polym.Sci,69 1385

8. R.G.Raj, B.V.Kokta, D.Maldas and C.Daneult, J. Appl.Polym.Sci, 37 (1989) 1089

9. M.Paaw and M. Lurius, J. Appl.Polym.Sci., 51 (1994) 127

10.S.Fellahi, N.Chikhi, M. Baker, J. Appl.Polym.Sci, 82 (2001)861

11.C. Hepburn, Plast. Rubber. Int, 9(1984)11

12.B.Pukanszki, E.Fekete, Poly.Compos,6(1998)313

13.K.W.Y Wong, R.W. Truss, Comp.Sci and Tech, 52(1994)361

14.A.M.Riley, C.D.Paynter, P.M.McGenity and J.M.Adams, Plast and Rubb.Process and Applications, 14(2) (1990) 85

15.L.Jilken, G.Malhmmar and R.Selden, Polym. Testing, 10 (1991) 329

16.Jun Kyung Kim, R.E. Robertson, J.Mater.Sci 27(1992)161

17.H.Nakagawa, H.Sano, Polym. Prepr.,26(1982)249 
Table 1. Chemical composition of Granite powder.

$\begin{array}{cc}\text { Compound } & \text { Wt.\% } \\ \text { Silica } & 70-77 \\ \text { Alumina } & 11-13 \\ \text { Potassium oxide } & 3-5 \\ \text { Soda } & 3-5 \\ \text { Lime } & 1 \\ \text { Iron } & 2-3 \\ \text { Magnesia \& Titania } & \text { Less than 1 }\end{array}$

Table 2. Tensile, Flexural, Compression and Impact properties of epoxy toughened with PBT blend matrix.

\begin{tabular}{|c|c|c|c|c|c|c|c|c|}
\hline \multirow{2}{*}{$\begin{array}{l}\% \text { of PBT } \\
\text { content in } \\
\text { epoxy }\end{array}$} & \multicolumn{3}{|c|}{ Tensile properties } & \multicolumn{2}{|c|}{ Flexural properties } & \multicolumn{2}{|c|}{ Compression properties } & \multirow{2}{*}{$\begin{array}{l}\text { Impact } \\
\text { strength }\end{array}$} \\
\hline & $\begin{array}{c}\text { Tensile } \\
\text { strength } \\
\mathrm{MPa}\end{array}$ & $\begin{array}{c}\text { Tensile } \\
\text { modulus } \\
\mathrm{MPa}\end{array}$ & $\begin{array}{c}\% \\
\text { elongation } \\
\text { at break }\end{array}$ & $\begin{array}{c}\text { Flexural } \\
\text { strength } \\
\mathrm{MPa}\end{array}$ & $\begin{array}{c}\text { Flexural } \\
\text { modulus } \\
\text { Mpa }\end{array}$ & $\begin{array}{l}\text { Compression } \\
\text { strength } \mathrm{MPa}\end{array}$ & $\begin{array}{l}\text { Compression } \\
\text { modulus } \\
\text { Mpa }\end{array}$ & \\
\hline 0 & 18.6 & 525 & 4.0 & 45.9 & 640 & 48.4 & 2931 & 30 \\
\hline 1 & 27.5 & 563 & 7.0 & 50.0 & 1064 & 93.0 & 3663 & 40 \\
\hline 2 & 38.5 & 606 & 6.4 & 55.6 & 1143 & 104.4 & 3730 & 45 \\
\hline 3 & 35.0 & 523 & 5.4 & 54.2 & 1138 & 96.0 & 3867 & 36 \\
\hline 4 & 30.4 & 493 & 4.5 & 49.6 & 905 & 89.3 & 4744 & 28 \\
\hline
\end{tabular}


Table 3.Chemical resistance properties of Untreated, coupling agent treated and epoxy/granite powder composites. (Percentage of filler content in matrix by wt.)

Chemicals

Untreated Treated Untreated Treated Untreated Treated Untreated Treated

\begin{tabular}{|c|c|c|c|c|c|c|c|c|}
\hline Acetic acid & 0.60 & 0.59 & 0.54 & 0.53 & 0.52 & 0.51 & 0.51 & 0.49 \\
\hline $\begin{array}{l}\text { Hydrochloric } \\
\text { acid }\end{array}$ & 1.29 & 1.11 & 1.18 & 1.17 & 101.7 & 1.16 & 1.16 & 1.15 \\
\hline Nitric acid & Dissolved & Dissolved & Dissolved & Dissolved & Dissolved & Dissolved & Dissolved & Dissolved \\
\hline $\begin{array}{l}\text { Sodium } \\
\text { hydroxide }\end{array}$ & 0.17 & 0.16 & 0.12 & 0.11 & 0.10 & 0.09 & 0.09 & 0.08 \\
\hline $\begin{array}{l}\text { Sodium } \\
\text { carbonate }\end{array}$ & 0.39 & 0.30 & 0.31 & 0.30 & 0.21 & 0.19 & 0.19 & 0.18 \\
\hline Benzene & 0.07 & 0.07 & 0.06 & 0.06 & 0.01 & $\begin{array}{c}\text { No } \\
\text { change }\end{array}$ & $\begin{array}{c}\text { No } \\
\text { change }\end{array}$ & $\begin{array}{c}\text { No } \\
\text { change }\end{array}$ \\
\hline $\begin{array}{l}\text { Carbon tetra } \\
\text { chloride }\end{array}$ & No change & $\begin{array}{c}\text { No } \\
\text { change }\end{array}$ & $\begin{array}{c}\text { No } \\
\text { change }\end{array}$ & $\begin{array}{l}\text { No } \\
\text { change }\end{array}$ & $\begin{array}{l}\text { No } \\
\text { change }\end{array}$ & $\begin{array}{l}\text { No } \\
\text { change }\end{array}$ & $\begin{array}{c}\text { No } \\
\text { change }\end{array}$ & $\begin{array}{c}\text { No } \\
\text { change }\end{array}$ \\
\hline Toluene & 0.08 & 0.07 & 0.06 & 0.06 & 0.05 & 0.04 & 0.05 & 0.05 \\
\hline Lactic acid & 0.39 & 0.31 & 0.23 & 0.20 & 0.11 & 0.96 & 0.10 & 0.09 \\
\hline
\end{tabular}


Table 4. Chemical resistance properties of 2\% PBT toughened epoxy/granite powder composites.

Percentage of filler content in the matrix by wt

Chemicals $\%$ PBT in
Epoxy Blend

30

40

50

60

Acetic acid

2.09

0.55

0.30

0.17

0.05

Hydrochloric

0.34

0.49

0.37

0.30

0.30

acid

Nitric acid

$-6.64$

30.47

21.59

14.62

9.91

Sodium

$-0.14$

$-0.13$

$-0.07$

$-0.13$

$-0.02$

hydroxide

0.02

No Change

0.01

0.02

0.04

carbonate

0.01

$-0.16$

$-0.05$

No Change

$-0.09$

Carbon tetra

$-0.07$

$-0.28$

$-0.10$

$-0.01$

$-0.02$

Toluene

$-0.05$

$-0.20$

$-0.07$

$-0.02$

$-0.08$

Lactic acid

0.06

0.16

0.39

0.01

$-0.04$ 


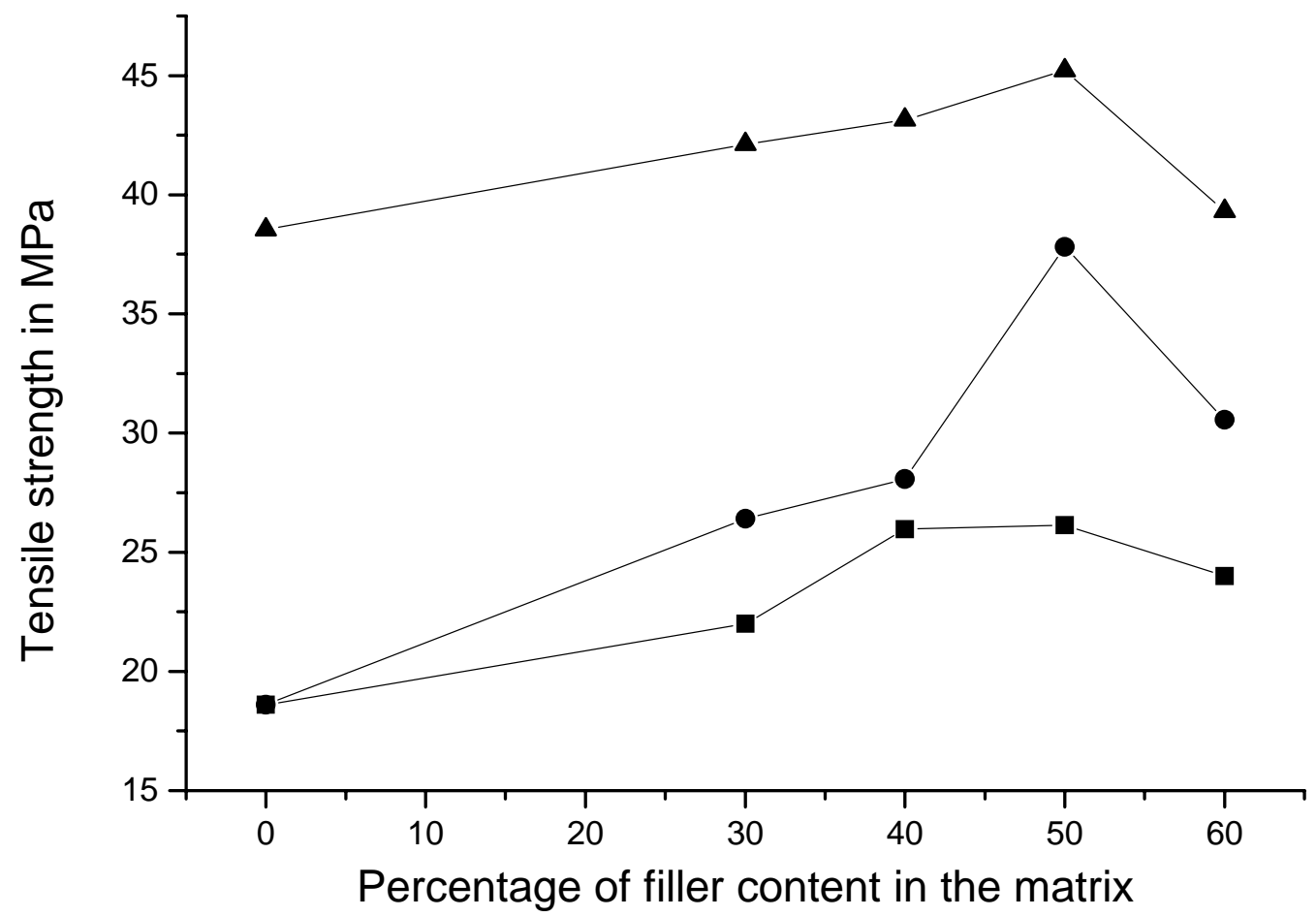

Fig. 1. Variation of tensile strength of untreated (घ), coupling agent treated $(\bullet)$ and 2 wt $\%$ PBT toughened epoxy ( $\mathbf{\Delta})$ with filler content. 


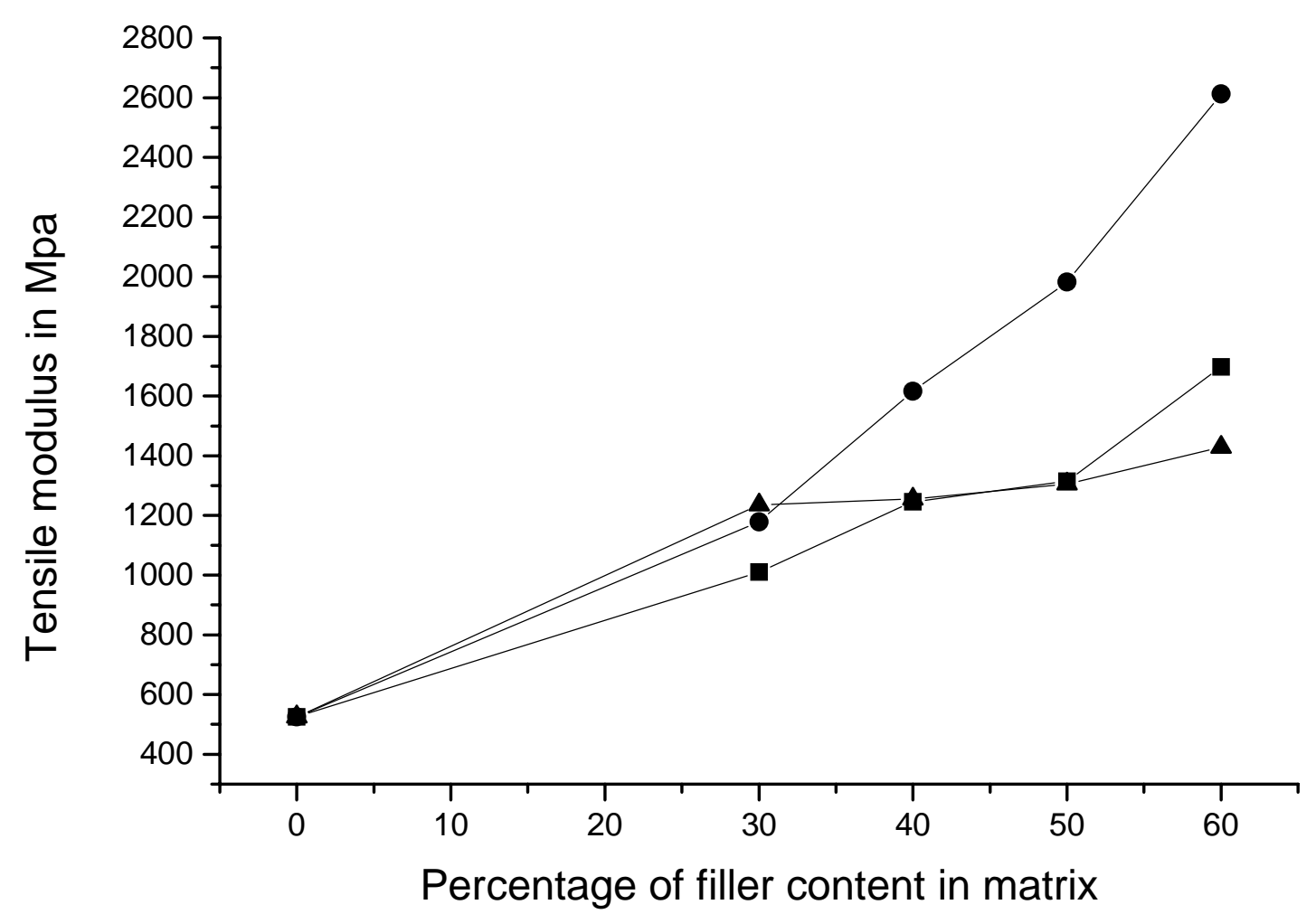

Fig. 2. Variation of tensile Modulus of untreated (a), coupling agent treated $(\bullet)$ and $2 \mathrm{wt} \%$ PBT toughened epoxy $(\boldsymbol{\Delta})$ with filler content. 


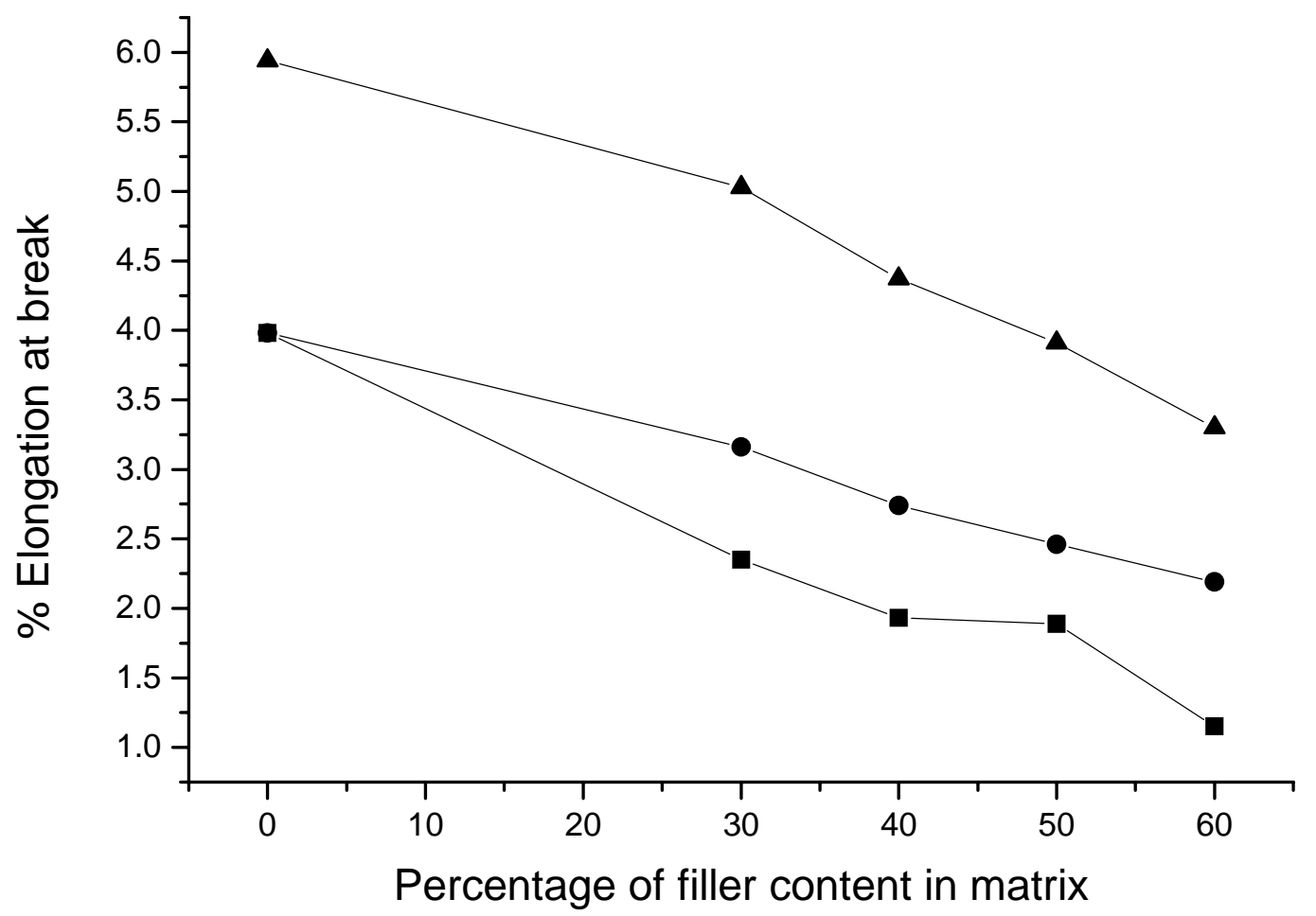

Fig. 3. Variation of tensile elongation of untreated (-), coupling agent treated (•) and $2 \mathrm{wt} \%$ PBT toughened epoxy $(\boldsymbol{\Lambda})$ with filler content. 


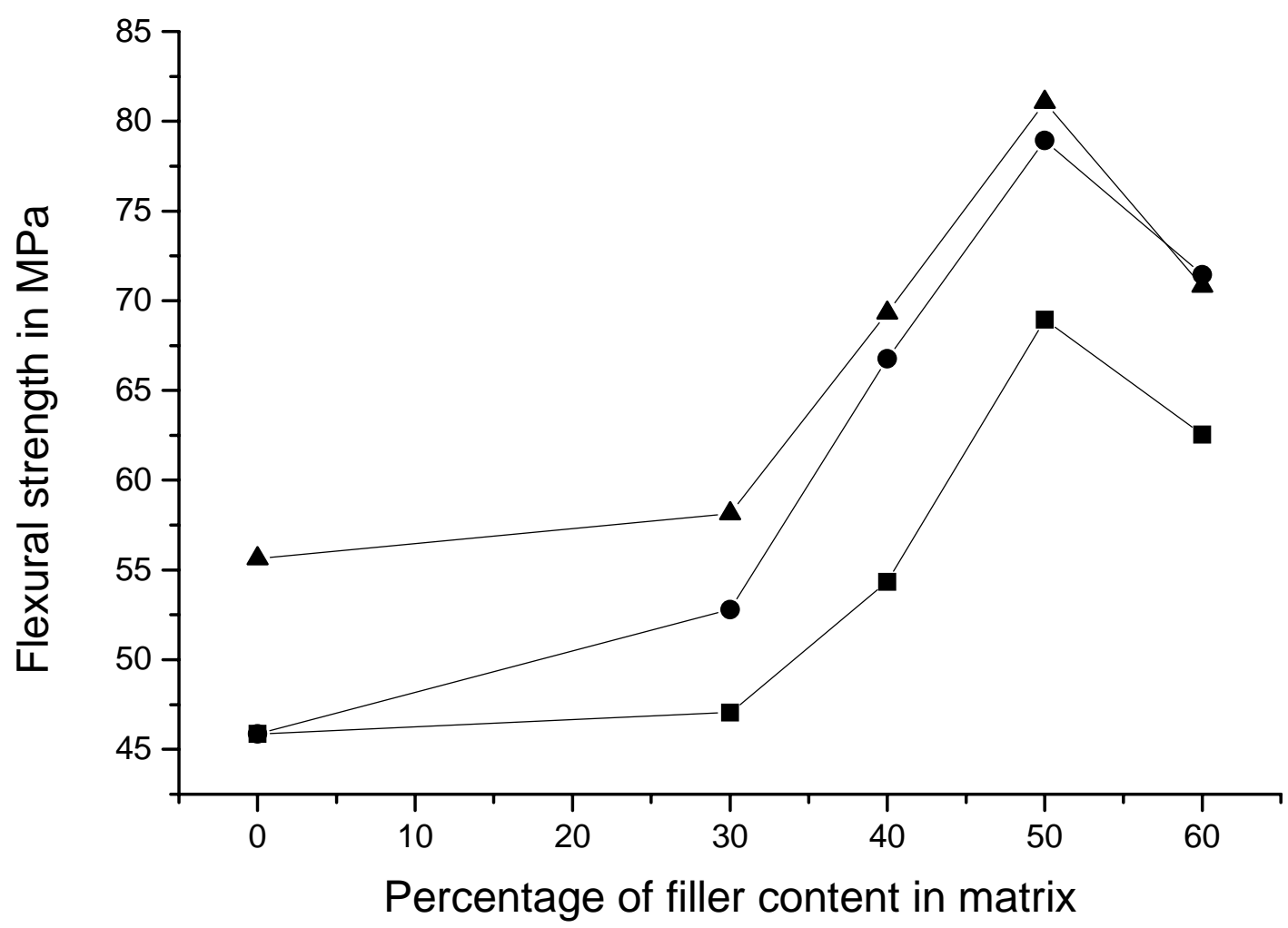

Fig. 4. Variation of flexural strength of untreated (घ), coupling agent treated $(\bullet)$ and $2 \mathrm{wt} \%$ PBT toughened epoxy ( $\boldsymbol{\Delta})$ with filler content. 


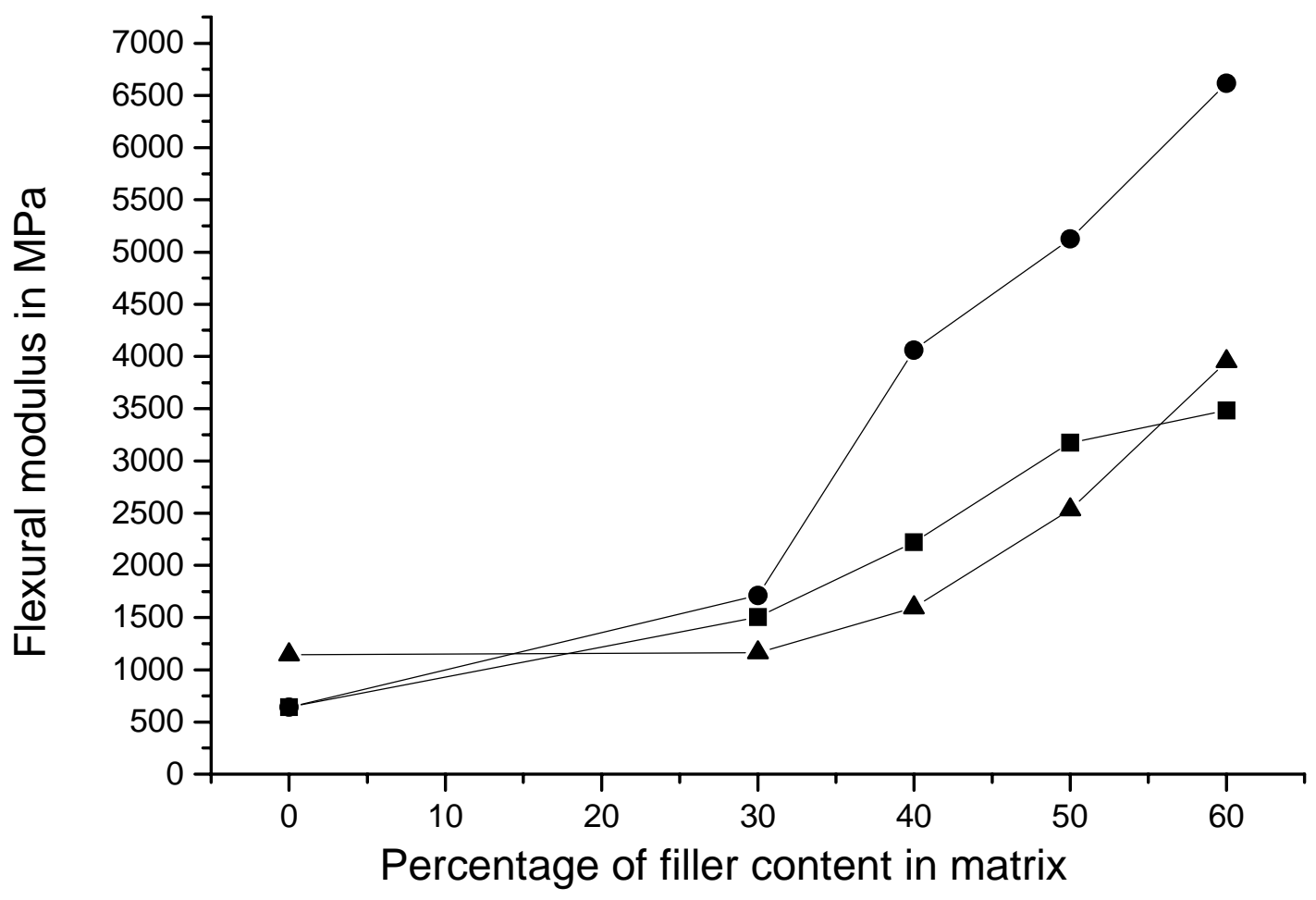

Fig. 5. Variation of flexural modulus of untreated (घ), coupling agent treated (•) and $2 \mathrm{wt} \%$ PBT toughened epoxy $(\boldsymbol{\Delta})$ with filler content. 


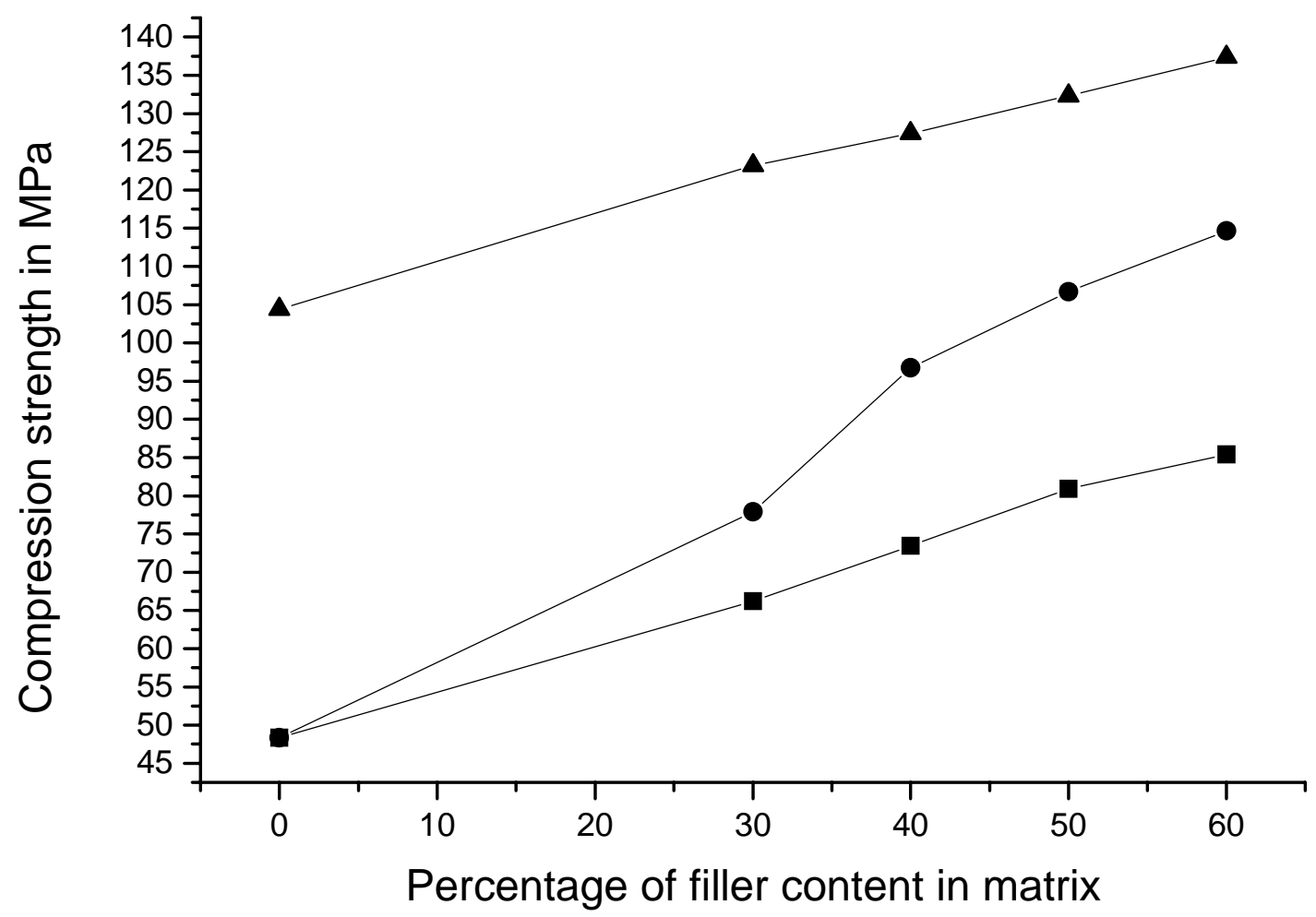

Fig. 6.Variation of compression strength of untreated $(\boldsymbol{\bullet})$, coupling agent treated $(\bullet)$ and 2 wt $\%$ PBT toughened epoxy ( $\boldsymbol{\Delta}$ ) with filler content. 


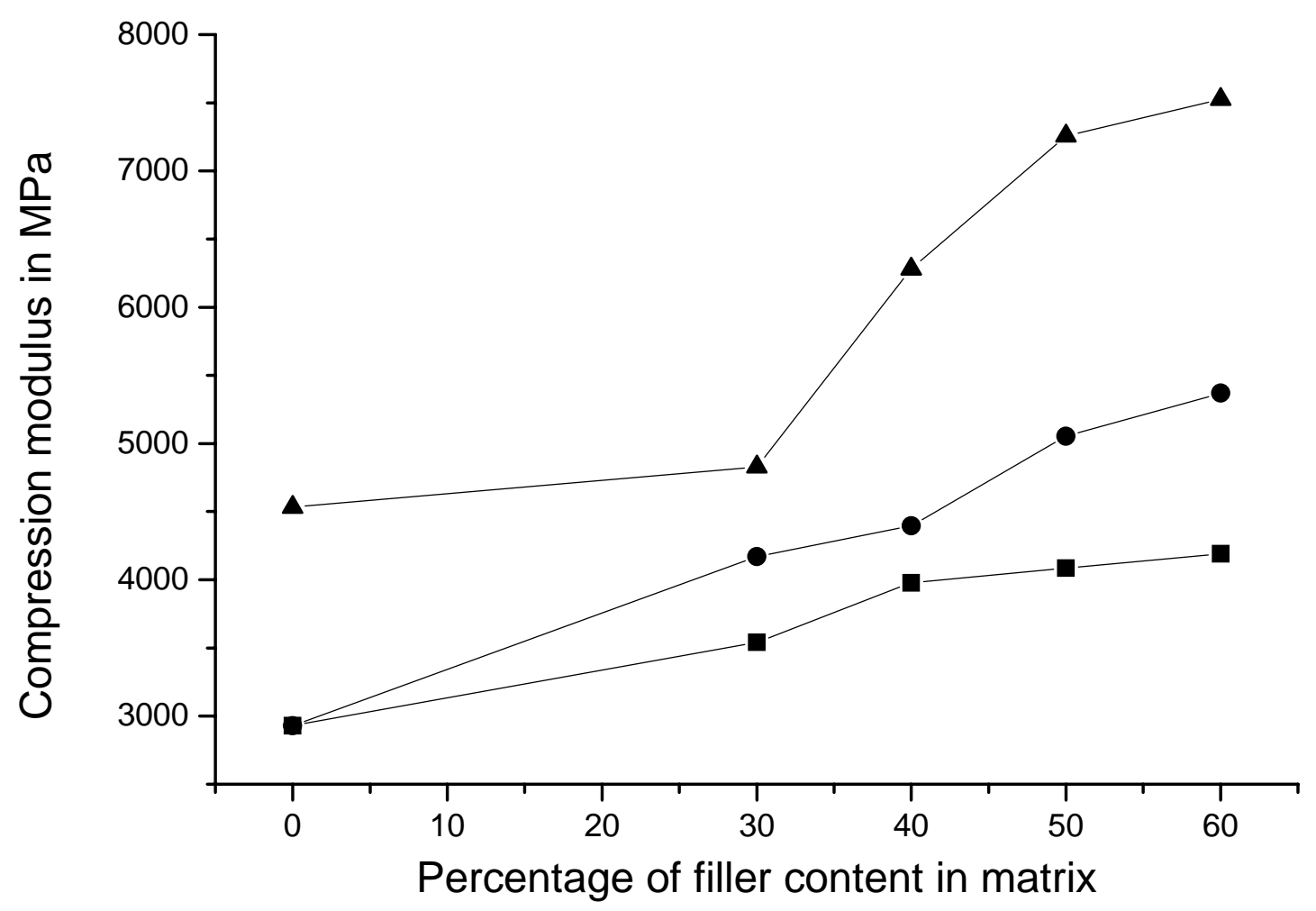

Fig. 7. Variation of compression modulus of untreated ( $\boldsymbol{\bullet})$, coupling agent treated $(\bullet)$ and 2 wt $\%$ PBT toughened epoxy ( $\boldsymbol{\Delta})$ with filler content. 


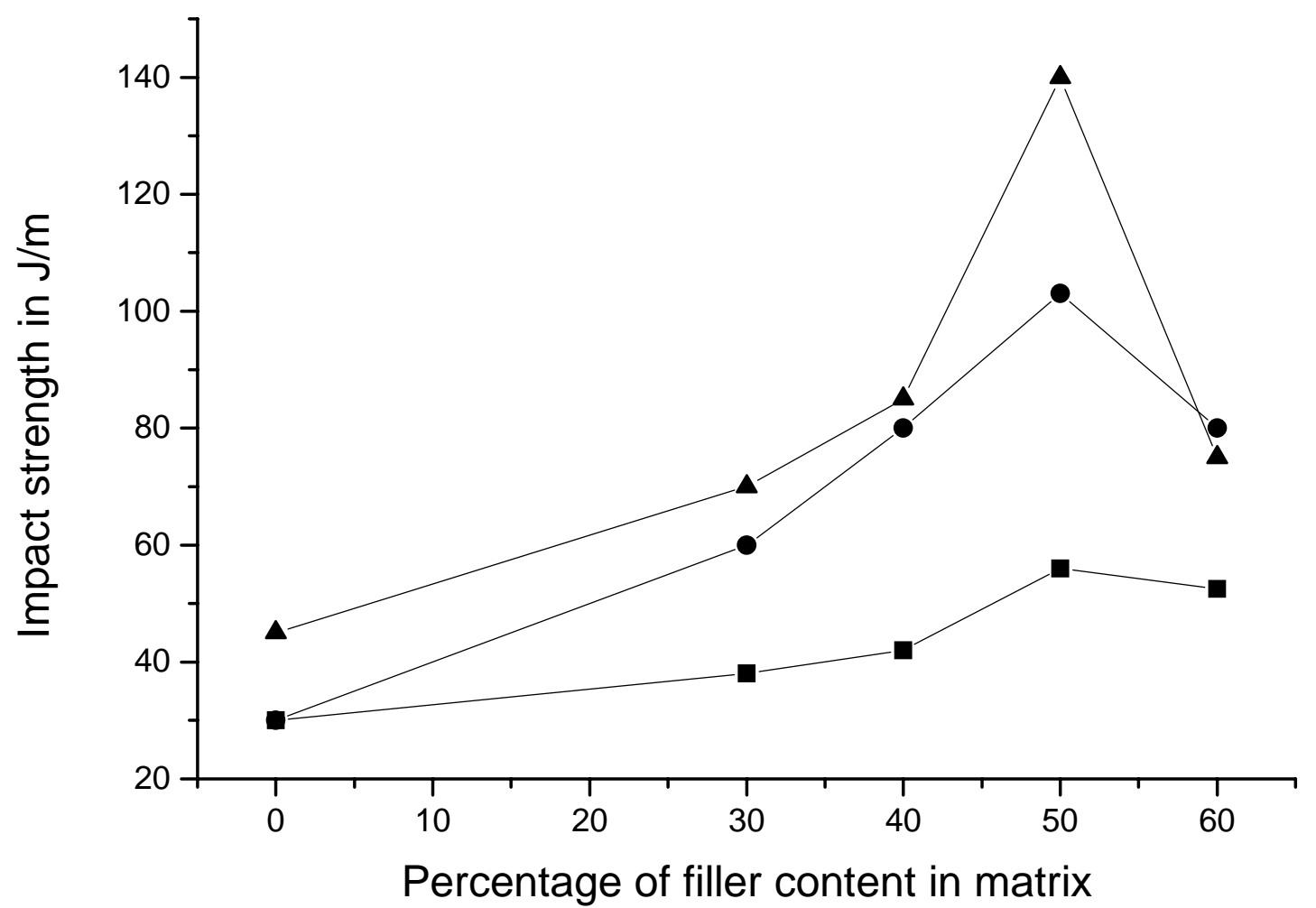

Fig. 8.Variation of impact strength of untreated ( $\mathbf{\square})$, coupling agent treated $(\bullet)$ and $2 \mathrm{wt} \%$ PBT toughened epoxy ( $\boldsymbol{\Delta})$ with filler content. 


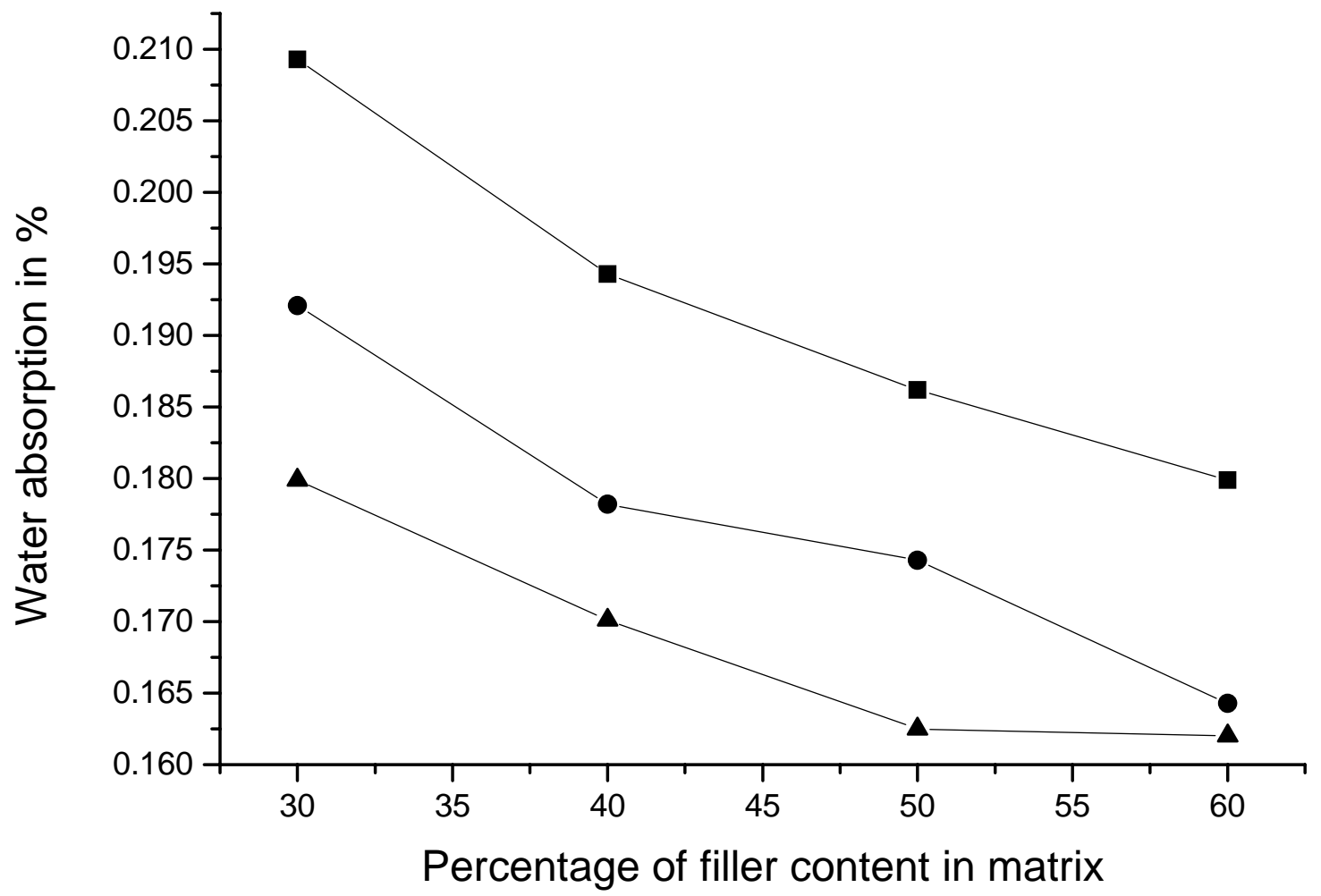

Fig. 9.Variation of water absorption of untreated ( $\bullet$ ), coupling agent treated $(\bullet)$ and 2 wt $\%$ PBT toughened epoxy $(\boldsymbol{\Delta})$ with filler content. 